\title{
MEIO SÉCULO DE RAE
}

Carlos Osmar Bertero carlos.bertero@fgv.br

Professor da Escola de Administração de Empresas de São Paulo, Fundação Getulio Vargas - São Paulo - SP, Brasil
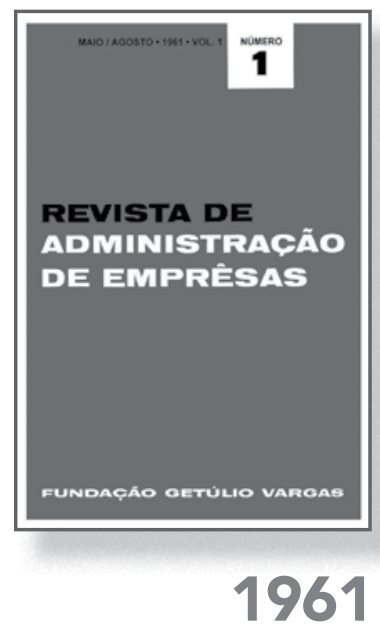

v. $1-n^{\circ} 1$ maio/ago.

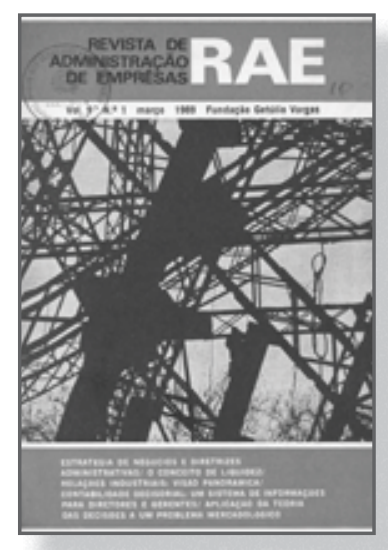

1969

n. 9 - $\mathrm{n}^{\circ} 1$ jan/mar.

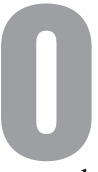

quinquagésimo aniversário de uma revista é sempre data para ser comemorada. Mais ainda quando se trata de um periódico científico, e com redobrada alegria e sentimento de triunfo se tal comemoração refere-se a um periódico brasileiro. Desdobremos e expliquemos as razões para triplicar a comemoração. Primeiramente, periódicos não são longevos. O número dos que se iniciam, mas depois atrasam e acabam por reduzir a frequência até o encerramento, não é pequeno. Um periódico científico que trata de Administração, área tradicionalmente vista como mais voltada à prática e à divulgação de Best Practices do que à indagação e à problematização, tende a ter vida ainda mais acidentada e possibilidades mais reduzidas de sobrevivência. $\mathrm{E}$, finalmente, sendo brasileiro, nascido num país onde a vida universitária começou com atraso, e há 50 anos, quando ainda tínhamos poucas universidades, mínimo de matrículas no ensino superior e poucas opções de cursos e profissões, nas quais a Administração não estava incluída. Na verdade, no momento em que introduziram no País os cursos de graduação em Administração, as profissões que se ofereciam aos jovens eram Medicina, Engenharia, Direito, Oficial das Forças Armadas e, se fosse do sexo masculino, Padre da Igreja Católica.

Ao sentar-me para redigir esta nota de aniversário de nossa revista, fui imediatamente ao volume 46, número 2 da $R A E$, porque lá se publicou um pequeno artigo de minha autoria, A $R A E$ nos seus 45 anos, no qual eu, então diretor e editor da revista, decidi celebrar os 45 anos. Não pensei então que seria solicitado a escrever material análogo para o cinquentenário da publicação. O que me leva a essa digressão é que não vejo muitas coisas a acrescentar àquilo que escrevi há cinco anos. Na verdade, a taxa de mudança nos tempos atuais é considerada elevada, mas não o suficiente para que considerações feitas há cinco anos sejam vistas como datadas. Peço ao leitor, portanto, que leia o que foi escrito há cinco anos porque não haverá muitas adições no que aqui escreverei.

Durante 50 anos, a RAE mantém a característica de ser uma revista da Escola de Administração de Empresas de São Paulo
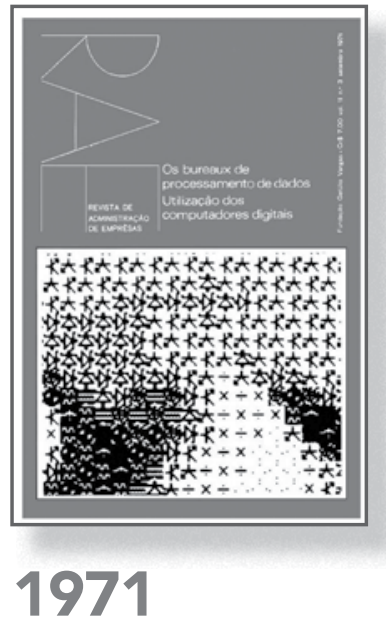

v. $11-n^{\circ} 3$ setembro


v. $24-n^{\circ} 3$

jul/set. 

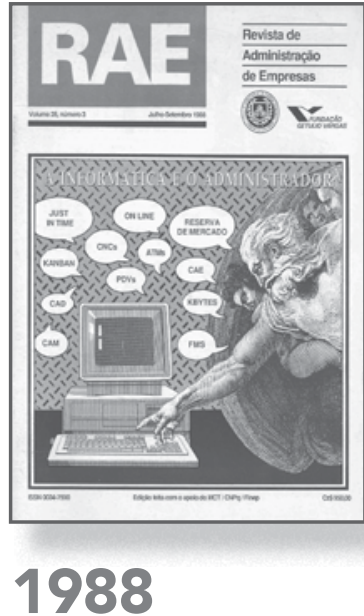

v. $28-n^{\circ} 3$

jul/set.
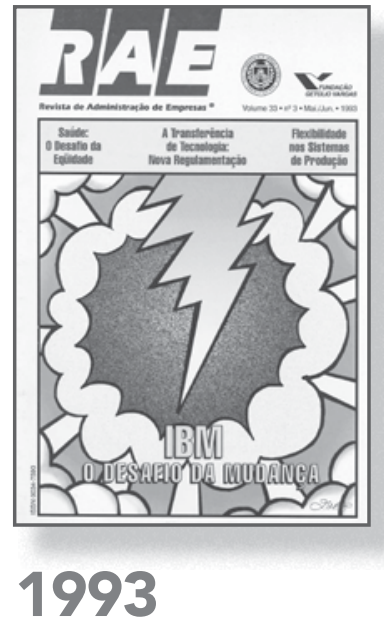

v. $33-n^{\circ} 3$ maio/jun.
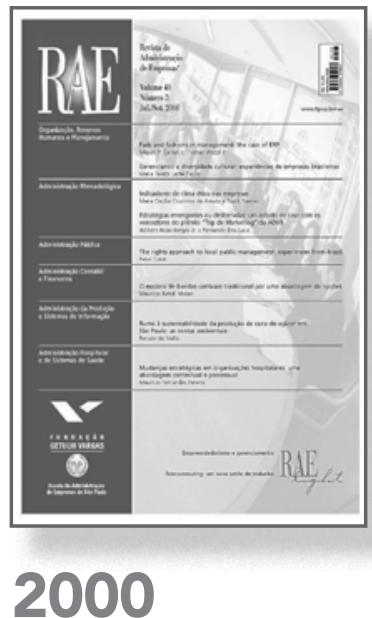

v. $40-n^{\circ} 3$

jul/set.


v. $51-n^{\circ} 1$

jan/fev.

(EAESP) da Fundação Getulio Vargas. A Escola foi fundada em 1954, e o seu curso de graduação formou sua primeira turma no início da década de sessenta. Isso indica que o projeto de se criar uma revista foi para ser executado simultaneamente com o curso de graduação. Mais significativo ainda é que a revista foi colocada como órgão de um Centro de Pesquisas e Publicações (CPP). Ora, todas essas coisas, certamente no melhor estilo norte-americano, estavam em claro descompasso com a cultura e os mores acadêmicos então predominantes em nosso País.

A vida acadêmica, de maneira geral e nos países que nos serviram de referência, particularmente a França e, num passado mais recente, os Estados Unidos, não tinham no passado a ênfase que hoje vemos colocada na publicação. Os tempos do publish or perish são mais novos e permita-se dizer que havia ainda um predomínio da oralidade sobre o texto escrito.

Começando pelos graus acadêmicos. A burocratização do ensino com o acompanhamento de títulos de pós-graduação, de mestrado e doutorado é recente. Ícones da Administração, como o falecido Peter Drucker, eram portadores de um título de graduação e muitas das mais prestigiosas escolas de administração de negócios americanas tinham em seus corpos docentes, até o final dos anos sessenta do século passado, professores que eram apenas portadores de um diploma de graduação.

Entre nós, brasileiros, o doutoramento era um grau que só era buscado por pessoas que já estavam na vida acadêmica, como professores e pesquisadores, e que apresentavam suas teses como prova de terem atingido a maturidade intelectual. $\mathrm{O}$ escrever era visto com temor e tremor. Só se deveria escrever se realmente tivéssemos algo a dizer. O que predominava no interior das universidades era ainda um mundo de oralidade e se aconselhavam os jovens professores a que lessem e estudassem bastante, analisando e refletindo, e só publicassem já em fase tardia de suas carreiras. Quão tardia? Digamos que nunca antes dos meados dos 40 anos e, mais seguramente, a partir dos 50 anos de idade. Trabalho interessante e que ainda aguarda quem o faça é um levantamento das idades em que professores começavam a publicar naquela época. Tudo isso nos coloca a razoável distância do mundo acadêmico e escolar de nossos dias, quando se pede a alunos de graduação trabalhos "originais" ao final de uma disciplina e um Trabalho de Conclusão de Curso (TCC) para a conclusão de um curso de graduação ou para a obtenção do título de especialista num curso de pós-graduação lato sensu. Talvez o cotejo do que acontecia no passado com o que hoje ocorre auxilie na explicação da mais recente praga a assolar a academia, que é o Copy and Paste. Convenhamos que a maioria dos seres humanos passa pela vida sem nada de novo a dizer.

Naqueles tempos, portanto, $\mathrm{O}$ que atormentava um editor era não ter o que publicar. Toda a conjuntura era desfavorável à produção científica como hoje a conhecemos. Atualmente, o editor trabalha numa revista científica brasileira de primeiro nível em nossa área de Administração, com uma taxa de seletividade elevada, o que assegura um grande número de artigos para serem escolhidos. Com isso, constata-se que a $R A E$ foi alterando suas práticas editoriais em consonância com as transformações que foram ocorrendo no ambiente acadêmico.

Outra característica importante era a ausência de um blind peer review. As decisões eram inteiramente de competência do redator chefe ou simplesmente do editor responsável, que atuava como um monarca absoluto. Havia um Con- 
selho Editorial, mas, na maioria das vezes, isso era um ritualismo puramente formal.

Como revista que, de um início de periódico pioneiro, publicando materiais os mais diversos numa área recém-chegada ao Brasil, que era a Administração, à condição de periódico científico, ligado à comunidade que pratica o chamado stricto sensu, muitas transformações foram necessárias. Todas elas exigiram empenho editorial. O estabelecimento do peer review, mas especialmente a busca de materiais que a tornassem um canal por onde escoariam apenas artigos que fossem considerados cientificamente relevantes. Isso fez com que novas seções se abrissem e que, curiosamente, se criasse uma RAE-eletrônica, surgida por acúmulo de material de boa qualidade, mas que escoaria muito lentamente por meio de um periódico impresso, publicado apenas trimestralmente.

A $R A E$, no entanto, não seria poupada de uma característica de nossa cultura, a competitividade. Está claro que a $R A E$ foi estrela solitária nos seus primeiros anos de existência. As únicas revistas que poderiam reivindicar antecedência seriam a Revista da Administração da USP, lançada em 1947, e a Revista do Serviço Público, que começou a ser publicada em 1949. Ambas sofreram interrupções, voltando a ser publicadas regularmente depois da fundação da $R A E$. Atualmente, porém, a $R A E$ encontra concorrentes, e a disputa se dá com base na qualidade do que se publica. E, no mundo das métricas, prestigia-se o fator de impacto.

A $R A E$ é, de certa forma, uma sobrevivente enquanto revista generalista. Isso se explica pelo fato de ela ainda manter um traço de sua fundação, que era a de ser uma revista da EAESP e, para que a representatividade se mantivesse, era necessário que se publicasse mate- rial das diversas áreas de Administração. Uma análise de conteúdo da revista, entretanto, revelaria que certas áreas sempre se fizeram mais presentes do que outras. O momento de revistas generalistas de cunho científico, contudo, já passou. O generalismo se mantém em revistas de tipo "profissional". Exemplo excelente é a Harvard Business Review.

No mundo dos periódicos científicos, porém, no qual a $R A E$ inseriu-se de maneira definitiva, o generalismo internacionalmente, praticamente, já deixou de existir, cedendo o passo às revistas especializadas. Essa especialização ainda segue, em grande medida, as diversas áreas funcionais da Administração. Dessa maneira, temos revistas de finanças, marketing, gestão de recursos humanos, logística, operações, estratégia etc. Não seria descabido propor que se tentasse desenvolver outras publicações nas diversas especialidades, mantendo a $R A E$ focada no que talvez seja o centro da Administração, a saber, Management, que, no português brasileiro, ainda não logrou conquistar uma tradução adequada. O que mais se aproximaria seria dizer que a $R A E$ seria uma revista científica voltada à Gestão. Mas podemos deixar a tradução de lado e exemplificarmos o que se propõe olhando para as revistas da Academy of Management, que são marcadamente revistas de Management.

Várias notícias indicam profunda mudança no mundo do livro impresso, com o fechamento de livrarias nos Estados Unidos e a perspectiva sombria para as grandes redes de megastores. Considere-se ainda a informação de que a Amazon vendeu, no ano passado, mais e-books do que livros de papel e temos aqui uma inspiração de que a edições eletrônicas no site, que a $R A E$ já vem disponibilizando, siga-se a colocação da revista em tablets, kindles ou i-pads.
Outra proposta vai ao encontro da internacionalização ou globalização. O projeto de uma $R A E$ em língua inglesa deveria ser considerado. Há um esforço para que publiquemos em periódicos internacionais e, gradualmente, nossos professores e pesquisadores vão se fazendo presentes naqueles periódicos. Isso, entretanto, não basta num processo de inserção internacional. A China e a Índia criaram periódicos de Administração que são publicados em língua inglesa, mas que contêm material produzido por acadêmicos dos mais diversos países e não apenas dos países em que as revistas estão sediadas. Teria que ser uma $R A E$ Internacional, na qual fôssemos capazes de atrair colegas de outros países para que aqui publicassem.

Mas, afinal, basta de considerações e sugestões. O aniversário é o momento para que se parabenize e agradeça a todos aqueles que labutam na revista. Seu diretor e editor, Eduardo Diniz, a todos os que atuam no Conselho Editorial, ao pessoal de Administração e apoio, e não esquecendo os diversos referees que, silenciosa e anonimamente, trabalham para que a revista continue a existir.

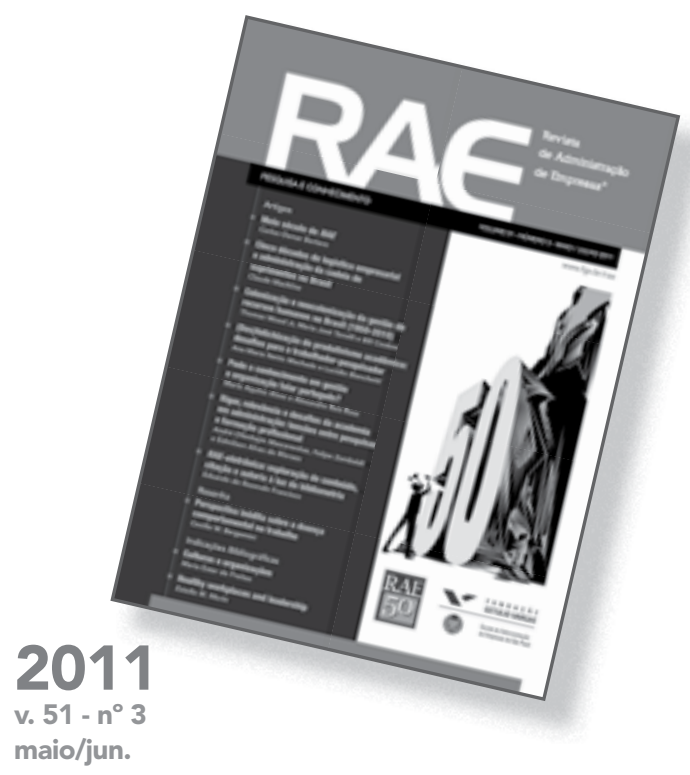

